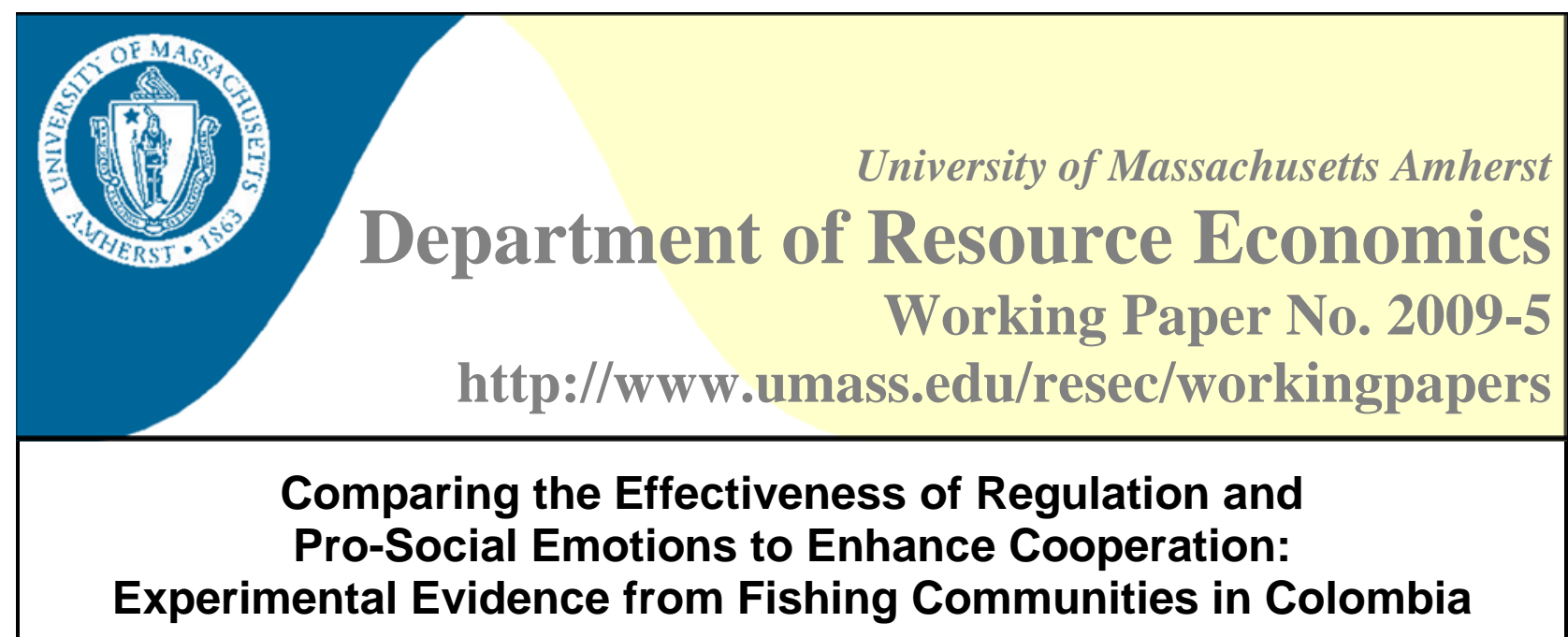

Maria Claudia Lopez ${ }^{1}$, James J. Murphy ${ }^{2}$, John M. Spraggon ${ }^{3}$, and John K. Stranlund ${ }^{4}$

Abstract:

This paper presents the results from a series of framed field experiments conducted in fishing communities off the Caribbean coast of Colombia. The goal is to investigate the relative effectiveness of exogenous regulatory pressure and pro-social emotions in promoting cooperative behavior in a public goods context. The random public revelation of an individual's contribution and its consequences for the rest of the group leads to significantly higher public good contributions and social welfare than regulatory pressure, even under regulations that are designed to motivate fully efficient contributions.

Keywords: public goods, field experiments, pro-social emotions, social dilemma, regulation, enforcement.

JEL Classification: C93, H41, Q20, Q28

\footnotetext{
${ }^{1}$ Maria Claudia Lopez, School of Environmental and Rural Studies

Pontifica Universidad Javeriana, Bogota, Colombia

E: mclopezperez@gmail.com

${ }^{2}$ James J. Murphy, Department of Economics

University of Alaska Anchorage, 201-D Rasmuson Hall

3211 Providence Drive, Anchorage, AK 99508

E: murphy@uaa.alaska.edu P: 907-786-1936 F: 907-786-4115

${ }^{3}$ John M. Spraggon, Department of Resource Economics

University of Massachusetts, 212F Stockbridge Hall

80 Campus Center Way, Amherst, MA 01003-9246

E: jmspraggon@resecon.umass.edu P: 413-545-6651 F: 413-545-5853

${ }^{4}$ John K. Stranlund, Department of Resource Economics

University of Massachusetts, 214 Stockbridge Hall

80 Campus Center Way, Amherst, MA 01003-9246

E: stranlund@resecon.umass.edu P: 413-545-6328 F: 413-545-5853
} 


\title{
Comparing the Effectiveness of Regulation and Pro-Social Emotions to Enhance Cooperation: Experimental Evidence from Fishing Communities in Colombia
}

\author{
MARIA CLAUDIA LOPEZ \\ School of Environmental and Rural Studies \\ Pontificia Universidad Javeriana \\ Bogotá, Colombia \\ JAMES J. MURPHY \\ Department of Economics \\ University of Alaska-Anchorage \\ JOHN M. SPRAGGON \\ Department of Resource Economics \\ University of Massachusetts-Amherst \\ JOHN K. STRANLUND \\ Department of Resource Economics \\ University of Massachusetts-Amherst
}

\begin{abstract}
* We are particularly grateful to Maria Alejandra Velez for her help with this research. In addition, the field research benefitted greatly from the efforts of Ana Maria Roldan, Laura Estevez, Melisa Arboleda and Juan Carlos Rocha. The experiments would not have been possible without the help of the fishermen associations of San Andres and Providencia that helped the research team to develop credibility with local community members. Additional credit is due the Secretaria de Pesca del Departamento de San Andres. Thanks are due the members of the School of Environmental and Rural Studies at Universidad Javeriana, Colombia for their ideas and support. Juan Camilo Cardenas provided critical comments on the experimental design. We also received valuable suggestions from James Boyce, Samuel Bowles and Elinor Ostrom. Wendy Varner and Susanne Hale provided administrative support. Financial support from the U.S. Embassy in Bogotá is gratefully acknowledged. We assume complete responsibility for the final contents of this paper.
\end{abstract}




\title{
Comparing the Effectiveness of Regulation and Pro-Social Emotions to Enhance Cooperation: Experimental Evidence from Fishing Communities in Colombia
}

\begin{abstract}
This paper presents the results from a series of framed field experiments conducted in fishing communities off the Caribbean coast of Colombia. The goal is to investigate the relative effectiveness of exogenous regulatory pressure and pro-social emotions in promoting cooperative behavior in a public goods context. The random public revelation of an individual's contribution and its consequences for the rest of the group leads to significantly higher public good contributions and social welfare than regulatory pressure, even under regulations that are designed to motivate fully efficient contributions.
\end{abstract}

JEL Codes: C93, H41, Q20, Q28

Keywords: public goods, field experiments, pro-social emotions, social dilemma, regulation, enforcement.

\section{INTRODUCTION}

This paper presents the results from a series of framed field experiments that were conducted in two fishing communities on two islands along the Caribbean coast of Colombia. The experiments were designed to compare the effectiveness in promoting efficient choices of social emotions, particularly feelings of guilt and shame, vis-à-vis externally-imposed regulatory controls. We are mainly interested in the value of external regulatory pressure to promote efficiency in environmental and natural resource settings in the developing world. Regulatory controls may not produce more efficient choices in communities in which individual emotions serve as brakes on purely self-interested behavior. 
Our notions of guilt and shame come from similar definitions employed by Bowles and Gintis (2003), Elster (1989, 1998), Hollander (2001), and Kandel and Lazear (1992). We define guilt as an internal penalty, or disutility, that one experiences when her non-cooperative behavior is not known by others in a society, whereas shame occurs when anonymity is removed and the individual's behavior is revealed to others. ${ }^{1}$ The key distinguishing feature between the two is that shame depends on the public revelation of individual behavior whereas guilt does not. Of course, guilt and shame have positive opposites — an individual may feel a sense of pride that comes from knowing that she has been cooperative and that feeling may be accentuated when her cooperative behavior is known to the rest of her community. These emotions can enhance cooperative behavior because they produce either internal sanctions for noncooperative behavior or internal rewards for cooperation. Such cooperation-enhancing emotions are often called prosocial emotions (Bowles and Gintis 2003).

Our work is closely related to other experimental studies that suggest that the desire to avoid social disapproval or gain social approval can enhance cooperative behavior. Gächter and Fehr (1999) show that avoiding social disapproval and peer pressure can induce cooperation when combined with some familiarity among subjects. Masclet et al. (2003) implemented a point system that individuals could use to express a degree of disapproval. Use of this system did not entail costs for those assigning points or receiving points. ${ }^{2}$ This simple way of communicating disapproval increased contributions to the public good. Rege and Telle (2004) find that the simple identification of subjects and their contributions to a public good, without giving other group members the ability to express approval or disapproval, tends to increase contributions in a one-shot public good game. ${ }^{3}$ In contrast, Noussair and Tucker (2007) suggest that the positive effects of publicly revealing individuals' contributions may rapidly deteriorate over time. 
The traditional response to correcting externalities generated by the divergence between individual and social well-being is to impose regulatory control to induce more efficient individual decisions. There is a significant literature on the effectiveness and efficiency of regulatory control — typically fixed quotas with some exogenous enforcement apparatus - on behavior in common property and public good games. This literature suggests that regulatory controls may not be effective at meeting the goal of increasing cooperative behavior. Ostmann (1998) finds that external regulation and enforcement financed by experiment participants only reduces harvests from a common pool by a small amount relative to a regulation-free environment. Beckenkamp and Ostmann (1999) report that high sanctions can cause overuse because subjects may perceive the high sanction as unfair. Cardenas et al. (2000) find that a quota supported by weak enforcement is effective in initial rounds, but the effectiveness of the regulation quickly erodes. Ostrom (2000) discusses how enforcement of externally-imposed rules may crowd out endogenous cooperative behavior because it may discourage the formation of social norms to solve the dilemma and at the same time may encourage players to cheat the system. Velez, Murphy, and Stranlund (forthcoming) demonstrate that regulatory control of a common pool resource under which community members can communicate with each other may be effective in some locations but counterproductive in others.

The basis of our experiments is a standard voluntary contribution game with which we ask whether realistic regulatory pressure promotes greater contributions to a public good than attempts to activate pro-social emotions. Since we are concerned with strategies to promote cooperation among environmental and natural resource users in the developing world, we conducted our experiments with fishermen and others who are intimately connected to local fishing in San Andres and Providencia, two islands off the Caribbean coast of Colombia. We 
framed the experiments as a situation in which each fisherman decides whether to help to clean the beaches and wharves. ${ }^{4}$ This is a critical issue for the fishermen of these islands because keeping the beaches and wharves clean prevents the migration of lobster and other species upon which the fishermen depend.

We conducted two regulation treatments, each of which required each individual to contribute all of one's tokens to the group. This requirement was backed by an exogenous enforcement strategy. After each round of play, individuals' contributions were audited with a probability of $1 / 5$ and a financial penalty was applied in cases of noncompliance. We chose a relatively low audit probability because low probabilities of detecting regulatory violations are characteristic of many environmental and natural resource policies in the developing world. The two regulation treatments differ with respect to the size of the penalty. One treatment used a low penalty that, in combination with the audit probability, would not be sufficient to induce compliance by risk neutral players. The other penalty was high enough to induce a risk neutral agent to fully comply with the requirement to contribute all of her tokens.

In an attempt to induce guilt for noncooperative behavior, we conducted another treatment in which individual choices were audited with the same $1 / 5$ probability as in our regulation treatments. An audited individual received information from the monitor in private about her contributions relative to the group's contributions, particularly the loss the individual imposed on the rest of the group because she did not contribute all her tokens. To induce shame, we conducted another treatment that was the same except the information about an audited individual's contribution decision was publicly revealed to the entire group. ${ }^{5}$ This treatment differs from others who have examined the role of social disapproval. First, revelation of an individual's choices was random, implying that any effects of shame involved the threat of 
public disclosure instead of certain disclosure as in Bohnet and Frey (1999), Rege and Telle (2004), Masclet et al. 2003, and Noussair and Tucker (2005 and 2007). Second, we did not allow group communication in any of our treatments. Thus, unlike Barr (2001) and Masclet et al. (2003), we did not give group members the ability to express disapproval. Thus, if shame had any effect on play in our public goods game, it is due to the threat of public disclosure of one's behavior rather than certain disclosure and the threat of a public sanction.

Our results suggest several insights into the roles of emotions and regulatory pressure in promoting more efficient provision of a public good. The most important is that the threat of public disclosure of individual contributions produced significantly higher contributions and social welfare than regulatory pressure. Even regulatory pressure that would normally be predicted to lead to efficient behavior produced lower contributions than the threat of public disclosure. Moreover, payoffs in the regulation treatments were much less than when individuals faced the threat of public disclosure not only because contributions were lower but also because of the penalties that individuals paid for violating the regulations. These results suggest a powerful conclusion about the value of regulatory pressure in social dilemmas in the developing world — communities in which there is some probability that individual behavior can be observed by others may reach more efficient outcomes than can be produced with regulatory pressure.

\section{EXPERIMENTAL DESIGN}

Our experiments are based on a standard linear voluntary contributions game with $n$ homogenous members of a group with identical monetary payoffs. Each individual, $i$, within a group received an initial endowment of $y$ tokens with which she decided how much to contribute to a group project, $g_{i}$, and how much to keep for herself. The sum of contributions to the group account is 
multiplied by a constant, $a$, and then distributed equally among all the group members. The payoff function for each participant is then

$$
\pi_{i}=y-g_{i}+(a / n) \sum_{i=1}^{n} g_{i} .
$$

We chose $a$ such that $a / n<1<a$, which leads to a dominant Nash strategy for each individual to contribute zero to the group account $\left(g_{i}=0\right)$, but the aggregate group payoff is maximized when each person contributes all of her tokens to the group project $\left(g_{i}=y\right)$.

When a regulator enforces a requirement that all individuals contribute all tokens to the group account, it applies a sanction of $s\left(y-g_{i}\right)$ on individual $i$ when it discovers $g_{i}<y$. The regulator can only observe an individual's contribution if it conducts an audit, which it does with probability $p$. A risk neutral individual's expected payoff is then

$$
\pi_{i}=y-g_{i}-p\left(\$-g_{i}\right)+(a / n) \sum_{i=1}^{n} g_{i} .
$$

Since $\partial \pi_{i} / \partial g_{i}=-1+p s+a / n$, an individual's Nash contribution is determined by

[3] $g=\left\{\begin{array}{l}y \text { if } p s>1-a / n \\ 0 \text { if } p s<1-a / n .\end{array}\right.$

The subjects in our experiments were placed in groups of $n=5$, and each group played 15 rounds under one of six treatments described below. ${ }^{6}$ The number of rounds was made known to the participants at the beginning of each experiment. For all treatments each subject received an initial endowment of $y=25$ tokens and the multiplier $a=2$. Thus, the marginal per capita return for contributing to the public good was $a / n=0.4$.

Once a group was gathered together, a monitor read the instructions to the group. ${ }^{7}$ Verbal communication among participants was not permitted in any treatment. The monitor first explained that each participant was going to be asked to make an economic decision and would earn tokens based on those decisions, and that the tokens would be converted to Colombian 
pesos at a rate of 25 pesos per token at the end of the session. The monitor also made it clear that participation in the experiments was completely voluntary, but that subjects would forfeit their payments if they quit before the end of the session. Participants with reading and/or writing difficulties received assistance, but they were required to make their contribution decisions on their own.

At the end of each session, earnings were converted to pesos and paid in cash to the participants. Individuals’ earnings ranged between 10,290 and 21,395 pesos with an average of 15,543 pesos (about US \$6.70 dollars). ${ }^{8}$ A show-up payment was not provided, but transportation expenses for the subjects were covered. A complimentary snack was offered as well. Each experiment lasted about two hours.

A total of 36 sessions, evenly divided among the six treatments, were conducted on the islands of San Andres and Providencia during September of 2005. A total of 180 individuals participated in our experiments, the majority of whom were men (84\%) because fishing is a male-dominated profession in Colombia. The average participant was a 36 year old male fisherman with nine years of formal schooling who has lived in the region for ten or more years.

Masclet et al. (2003) observe that the standard monetary sanction treatments, such as those in Fehr and Gächter (2000), potentially confound a formal system of monetary fines with a vehicle to express disapproval of others' decisions. In a similar vein, studies with an external regulation treatment (e.g. Cardenas et al. 2000) could potentially confound a public reminder about socially efficient choices with the financial consequences of noncompliance. The announcement of a regulatory standard provides a signal of socially desirable choices that could serve as a coordination device. The audit process requires a comparison, usually conducted in private, of the individual's choice with the standard. If there is a violation of the standard, then a 
preannounced exogenous financial penalty is imposed. Hence, it is possible that a simple comparison of external penalties with a standard regulation-free linear public goods game confounds these three effects. To avoid this potential problem, our experiments were designed in layers with each treatment building upon the previous, as shown in Table 1 and described below. $<<$ INSERT TABLE $1>>$

- Baseline. This was a standard public goods experiment in which each subject decided how to allocate her tokens between a private and a group account. In addition, at the end of each round, all individual contributions were posted on a board in random order with no personally identifying information. Hence, although all the individual choices were known, unlike Rege and Teller (2004) and Noussair and Tucker (2007), it was not possible to associate these choices with the individual group members.

- Frame: In addition to the procedures for the Baseline treatment, the frame treatment included a script read aloud to the entire group before each round that described the incentives of the game as follows:

"Before we begin playing for real money, I would like to point something out: As you may have noticed, the earnings for the group are the highest when everybody contributes 25 tokens to the group project. If you decide to keep tokens for yourself, you can increase your individual earnings but you are reducing the earnings of the group." 
This script is just cheap talk that should have no effect on choices. The Frame treatment is really the baseline against which the remaining four treatments should be compared since they all include this group reminder about socially efficient choices and free-riding incentives.

- Guilt (or Private Reminder). In addition to all the elements of the Frame treatment, at the end of each round one of the five subjects was randomly selected to receive the following private message about her choice in that round and how it affected the payoffs of the rest of the group:

\begin{tabular}{|l|l|}
\hline $\begin{array}{l}\text { The earnings of the group are the highest when everybody contributes all } \\
\text { of his or her } 25 \text { tokens to the group. }\end{array}$ \\
\hline Tokens you contributed to the group project. & \\
\hline Total tokens contributed to the project. & \\
\hline $\begin{array}{l}\text { Total tokens contributed to the project if you had } \\
\text { contributed your } 25 \text { tokens. }\end{array}$ & \\
\hline $\begin{array}{l}\text { Losses for the group because you did not contribute all of } \\
\text { your } 25 \text { tokens. }\end{array}$ & \\
\hline
\end{tabular}

If the person contributed all of her tokens, then she received a note saying: "You contributed all your 25 tokens to the project, which means you did all you could to make the earnings for the group the highest.” To guarantee that no one else in the group knew who received this information about how their choices affected the payoffs of the group, the other four group members received the same piece of paper but the right column was blank. 
- Shame (or Public Revelation). This treatment is essentially the same as the Guilt treatment, except that the message about how the randomly selected individual's contribution affected the payoff of the group was read aloud for everyone in the group to hear. Thus, if individual contributions under this treatment differ from the Guilt treatment it is because of the threat of public revelation of one's behavior and its consequences for the rest of the group.

- Low Penalty. As in the Guilt and Shame treatments, at the end of each round one individual was randomly selected to be audited. This treatment builds upon the Guilt treatment since the randomly selected individual received the same private reminder about the consequences of her choice. In addition, there was a requirement that each individual fully contribute to the group project $\left(g_{i}=y\right)$. If the audited person did not contribute all of her tokens to the group project, then she was penalized one token $(s=1)$ for every token she did not contribute to the group account (i.e., a one token fine for each token in the private account). The audit results were kept private. The expected marginal penalty under this treatment was $p s=1 / 5$, while the marginal value of violating the requirement to contribute all of one's tokens is $1-a / n=3 / 5$. From [3], therefore, a risk neutral subject's dominant Nash strategy under this treatment is still to contribute zero tokens to the group account $g_{i}=0$.

- High Penalty. This treatment is the same as the Low Penalty treatment, except that the marginal penalty for violating the requirement to contribute all of one's tokens was four tokens $(s=4)$. Since the expected marginal penalty under this treatment was $p s=4 / 5$, which exceeds the marginal value of violating the requirement of $1-a / n=3 / 5$, a risk neutral subject's dominant Nash strategy under this treatment is to fully comply with the requirement 
and contribute all of her tokens to the group account, $g_{i}=\mathrm{y}$. Note that this is the only one of the six treatments that a standard theory of risk-neutral, payoff-maximizing behavior would predict would be efficient.

\section{RESULTS}

Figures 1 presents a time series of average individual contributions to the group project by treatment, and Figure 2 shows expected individual earnings. ${ }^{9}$ Averages for all rounds are shown in Table 2. These charts suggest some interesting patterns in the data that we investigate more rigorously shortly. For the first five rounds, average contributions to the group project are roughly the same for the Shame, Low Penalty and High Penalty treatments, about $75-80 \%$ of the endowment. However, in subsequent rounds, contributions in the Shame treatment are consistently the highest. That average contributions to the group project under the Shame treatment (20.2) tend to be higher than under the Low and High Penalty treatment (18.2 and 18.5, respectively) suggests that the threat of public disclosure may have a greater impact on contributions than the threat of a monetary sanction, even with a High Penalty that was structured to induce risk-neutral payoff-maximizing individuals to contribute all of their tokens. Since average contributions are highest under the Shame treatment, average earnings (45.2) are highest as well. Average earnings under the High Penalty (38.3) treatment are lower than any other treatment, including the Baseline. This is a bit surprising because this is the only treatment in which, theoretically, every individual should contribute all of their tokens to the group account

and, therefore none should be penalized. Although, more participants were perfectly compliant in the High Penalty treatment (176 of 450) than in any other treatment, average earnings are lower due to the heavy penalties individuals paid by those who did not fully contribute. There is no 
statistical difference in the rate of compliance for the Shame treatment (165 of 450, $p=0.49$ ), but the absence of fines leads to higher earnings.

$<<$ INSERT TABLE $2>><<$ INSERT FIGURE $1>><<$ INSERT FIGURE $2>>$

To analyze our data more rigorously, Table 3 presents the results from two random effects Tobit models of the form $y_{i t}=x_{i t} \beta+v_{i}+\varepsilon_{i t}$ in which $x_{i t}$ is a vector of fixed effects, $v_{i} \sim N\left(0, \sigma_{v}^{2}\right)$ are the random effects, and $\varepsilon_{i} \sim N\left(0, \sigma_{\varepsilon}^{2}\right)$. In the first model in Table 3 , the dependent variable $y_{i t}$, is individual contributions, $g_{i t} \in[0,25]$; the dependent variable in the second model is individual earnings, $\pi_{i t} \in[0,65]$. For these regressions we divided the 15 rounds of each experiment into 3 intervals: the First interval included the first 5 rounds, the Middle interval included rounds 6 through 10, and the Last interval included the last five rounds. We interacted these time intervals with each of the fixed effect treatment variables. The omitted treatment variable is the Baseline. The results in Table 3 do not include the time intervals interacted with the Baseline because a separate regression indicated that contributions and earnings were unchanged over time in this treatment (this can also be observed in Figures 1 and 2). ${ }^{10}$ Eliminating the time interval interaction with Baseline greatly simplifies the interpretation of the constant in these regressions: the average contributions and average earnings over all rounds under the Baseline treatment. All of the remaining coefficients in Table 3 are interpreted as deviations from the Baseline. Let us now turn to the main results of our study.

$<<$ INSERT TABLE 3>> 
Result 1 (Frame): Informing subjects that contributing all tokens to the group project maximizes aggregate earnings did not affect average contributions or earnings, but did alter the distribution of decisions.

The Frame treatment differs from our Baseline treatment only in that we explicitly told subjects in the Frame experiments that their group’s payoff would be maximized if they contributed all of their tokens to the group project. The regression results in Table 3 suggest that this message had a small positive, but not statistically significant, effect on contributions and earnings (i.e., none of the Frame coefficients are significant). This suggests that simply telling the subjects that the efficient outcome is reached when they all contribute all of their tokens does not have an effect on average outcomes. However, it would be incorrect to conclude that the Frame has no impact on decisions. Figure 3 presents the distribution of contribution decisions for each treatment. In the Frame treatment, there is a pronounced increase in the frequency of "high" contributions in the 20-25 token range compared to the Baseline. Interestingly, there are also more noncompliant subjects in the Frame treatment. It appears that the script essentially shifted contribution decisions from the middle to the two extremes while preserving the mean. A KomolgorovSmirnov test confirms that the two distributions are statistically different $(p=0.00)$. $<<$ INSERT FIGURE 3>>

Result 2 (Guilt): The random private reminder of one's contribution decision did not affect average contributions or earnings.

The Guilt treatment differs from the Frame treatment in one way: after each round a single individual was randomly selected to receive a private message about the negative consequence of her contribution on the payoffs of the rest of the group. The results in Table 3 show that 
individual contributions and earnings under the Guilt treatment were not significantly different from the Baseline in the First and Middle time intervals, but were significantly higher in the Last time interval. The most relevant comparison though is with the results under the Frame treatment. Contributions and earnings under the Guilt treatment were not significantly different than the Frame treatment in the First interval $(p=0.88$ and $p=0.95$ for contributions and earnings respectively), in the Middle interval ( $p=0.90$ and $p=0.82$ ), and in the Last interval ( $p$

$=0.23$ and $p=0.18) .{ }^{11} \mathrm{~A}$ Komolgorov-Smirnov test indicates that there is no difference between the two distributions of contribution decisions $(p=0.34)$. It therefore appears that adding a private reminder to randomly selected individuals has little impact on outcomes relative to just a general announcement to the group about efficient choices.

\section{Result 3 (Shame): The random public revelation one's contribution decision yielded significantly higher average contributions and earnings.}

The Shame treatment differs from the Guilt treatment in that the message a randomly selected individual received about the affects of her contributions on the rest of the group was read aloud, rather than being kept private. Thus, the entire group knew which individual was selected and how that individual's behavior affected earnings. It is clear from the regressions in Table 3 that the simple threat that one's choices and their consequences would be revealed to the rest of the group had significantly positive impacts on both contributions and individual earnings relative to the Baseline. Again, however, the most relevant comparison is with the Frame treatment. Individual contributions to the group project in the Shame treatment are significantly higher than under the Frame treatment in all three time intervals ( $p=0.04, p=0.00, p=0.00$ for First, Middle, Last respectively). As one would expect, the higher contributions in the Shame treatment also 
lead to higher individual earnings in all time intervals ( $p=0.03, p=0.00, p=0.00$ ). Shame treatment contributions and earnings are also consistently higher than the Guilt treatment.

Our results concerning the positive effects of the public revelation of choices and consequences differ from recent work by Noussair and Tucker (2007). They find that publicly revealing all subjects' contributions increased contribution in early rounds, but that contribution levels quickly fell over time. They also find this effect with their Non-Monetary Punishment treatment in Noussair and Tucker (2005). In contrast, average contributions and earnings in our Shame experiments were slightly higher in the later rounds (also see Figure 1). Several differences between our experiments and Noussair's and Tucker's could explain the different results. First, Noussair and Tucker revealed every individual's contribution while we revealed the contribution of a single randomly chosen individual. It may be that the threat of being singled out for scrutiny is a more powerful and lasting motivator than being scrutinized along with everyone else your group. Second, while Noussair and Tucker only revealed individual contributions, we also revealed how an individual's contribution produced a loss for the rest of the group if the individual did not contribute all of their tokens. This decidedly negative spin on not contributing tokens to the group project, in combination with the threat of being singled out, may have kept contributions from deteriorating over time. Finally, Noussair and Tucker conducted neutrally-framed experiments with college students, while our experiments were mainly with fishermen and were framed to closely resemble a problem they routinely encounter. Moreover, the villagers in these communities typically interact and cooperate with each other on a variety of other similar issues. Thus, the positive and sustained impact of the threat of public revelation that we identify may be a manifestation of the social pressure and behavioral norms that these communities use to sustain cooperation in many areas of their daily lives. 


\section{Result 4: There is no difference in average contributions between the Low and High Penalty treatments.}

Recall that the expected marginal penalty under the Low Penalty treatment $(0.20$ tokens per unit violation) was not high enough to motivate a risk-neutral payoff-maximizing individual to comply with the requirement to contribute all of her tokens, but the expected marginal penalty under the High Penalty treatment (0.80 tokens) was high enough to induce perfect compliance by such an individual. Although the two regulation treatments have markedly different theoretical outcomes, there is no statistically significant difference in observed individual contributions in any of the three time intervals $(p=0.13, p=0.28, p=0.63)$. That contributions under the two treatments were essentially the same implies that the higher penalty for noncompliance played no role in increasing contributions despite the fact that, from the perspective of standard theory, the High Penalty regulation should have maximized contributions and earnings.

With the same average contribution decisions, but substantially greater fines in the High Penalty treatment, earnings are less than with the Low Penalty in all three time intervals ( $p=0.04$, $p=0.01, p=0.00$ ). In fact, as shown in Figure 2, the High Penalty treatment has the lowest average earnings of any treatment, including the Baseline, even though in theory it should yield the highest earnings. Earnings in the Low Penalty treatment start out slightly higher than the Baseline, but this benefit quickly decays leaving no difference in earnings between these two treatments in the later rounds. Likewise, there is no difference in earnings when comparing the Low Penalty and Frame treatments. Hence, these results concerning average individual earnings indicate that regulatory pressure did not make the groups better off. 
Our results about the effects of random monetary sanctions for violations of a requirement to contribute all of one's tokens warrants some skepticism about the value of regulatory pressure to improve the lot of small scale resource users in the developing world. One might argue that they improve social efficiency because they lead to higher contributions, at least with respect to the Baseline treatment, but it is clear that the increase in welfare that this produces is in large part transferred from the group to the larger society via the sanctions that noncompliant group members pay. Moreover, our final result suggests that regulatory pressure is unequivocally worse than the limited social pressure that arises from the Shame treatments.

\section{Result 5 (Shame): The threat of public revelation of one's choices led to significantly higher earnings than regulatory pressure.}

The threat of public revelation ended up being significantly better at enhancing group payoffs than any other treatment, including both regulatory treatments. In the First time interval, average earnings in the Shame treatment were statistically indistinguishable from those with a Low Penalty $(p=0.25)$, but exceed High Penalty earnings $(p=0.00)$. In the Middle and Last intervals, Shame treatment earnings are significantly greater than both Low and High Penalty earnings ( $p=0.00$ for all comparisons). Both the lower level of contributions and the fines for noncompliance in the two regulation treatments account for the erosion in group welfare.

\section{CONCLUSIONS}

The primary message of this work is a negative one concerning the performance of government interventions in small-scale resource industries in the developing world. Although each of our regulation treatments induced greater public good contributions relative to an unregulated 
baseline, neither of them outperformed the random public revelation of individual choices and their consequences for the rest of the group. This is particularly interesting because one of the regulation treatments was designed to maximize group payoffs. This regulation was nowhere near efficient, and its performance was dominated by the simple threat of public revelation. Therefore, in communities where there are mechanisms for triggering social emotions akin to shame, these emotions can support greater cooperation than regulatory pressure, even when regulations are designed to be efficient. In these situations a regulator would be better advised to leave the management of the natural resources to the community. Our results also point to an interesting question for future work-Does regulatory pressure complement or crowd-out social emotions in the management of natural resources?

We also claim contributions to the experimental literature on the effects of publicly revealing individual choices on levels of cooperation. One of the key elements of our design is that public revelation was a random event while, to our knowledge, other researchers reveal the choices of all individuals. Thus, the effects of public revelation that we find are due to individuals' perceptions of the threat of their behavior being revealed to the rest of their group, rather than the certainty of revelation. In many settings, including in the communities that motivate our research, random revelation is a more realistic way to approach this issue than revealing every individual's choices all the time. In our lives we simply are not perfectly informed of our neighbors' behavior as it concerns our well-being; we only observe their choices with some probability. This is also true of the communities in the developing world that motivate our research.

Finally, our choice to conduct framed experiments with the very individuals that we are interested in is certainly important. Given our interest in cooperative behavior in managing 
natural resources in the developing world, it is appropriate that we traveled to communities in the developing world and presented a social dilemma to individuals whose livelihoods are tied to the resolution of closely related dilemmas. The advantage of such framed field experiments is that subjects bring a context from their daily lives that could influence their behavior in the experiments, and that context is an important element of the question that is being addressed. The positive effects of randomly revealing individual choices, as well as the poor performance of our regulation treatments, may be influenced by the informal norms and sanctions that are important in the communities we visited, as well as their view of the government regulations they operate under. Disentangling these influences requires further research that combines field experiments and detailed knowledge of the lives of the subjects. 


\section{References}

Barr, Abigail. 2001. "Social Dilemmas and Shame-Based Sanctions: Experimental Results from Rural Zimbabwe.” The Centre for the Study of African Economies Working Paper Series. Working paper 149.

Beckenkamp, Martin and Axel Ostman. 1999. "Missing the Target? Sanctioning as an Ambiguous Structural Solution.” Resolving Social Dilemmas, Margaret Foddy, Michael Smithson, Sherry Scheneider and Michael Hogg Eds., Psychology Press, 165-180.

Bohnet, Iris, and Bruno Frey. 1999. “The Sound of Silence in Prisoner's Dilemma and Dictator Games.” Journal of Economic Behavior and Organization, 38(1), 43-57.

Bowles, Samuel, and Herbet Gintis. 2003. "Prosocial Emotions.” The Santa Fe Institute Working Paper Series, Working paper \# 02-07-028.

Cardenas, Juan Camilo, John K. Stranlund, and Cleve E. Willis. 2000. "Environmental Control and Institutional Crowding-out.” World Development, 28(10), 1719-1733.

Davis, Douglas, and Charles Holt. 1992. Experimental Economics. Princeton University Press, Princeton.

Elster, Jon. 1989. “Social Norms and Economic Theory.” Journal of Economic Perspectives, 3(4), 99-117. 
Elster, Jon. 1998. “Emotions and Economic Theory.” Journal of Economic Literature, 36(1), 47-74.

Falk, Armin, Ernst Fehr and Urs Fischbacher. 2001. “Driving Forces of Informal Sanctions.” Institute for Empirical Research in Economics, University of Zurich, Working paper \#59.

Fehr, Ernst, and Klaus Schmidt. 1999. “A Theory of Fairness, Competition and Cooperation.” Quarterly Journal of Economic, 114(3), 817-68.

Fehr, Ernst, and Simon Gächter. 2000. “Cooperation and Punishment in Public Goods Experiments.” American Economic Review, 90(4), 980-994.

Gächter, Simon, and Ernst Fehr. 1999. “Collective Action as a Social Exchange.” Journal of Economic Behavior and Organization, 39(4), 341-369.

Harrison, Glen W., and John List. 2004. “Field Experiments.” Journal of Economic Literature, 42 (4), 1009-1055.

Hollander, Heinz. 1990. “A Social Exchange Approach to Voluntary Cooperation.” American Economic Review, 80(5), 1157-1167. 
Kandel, Eugene, and Edward Lazear. 1992. "Peer Pressure and Partnership.” The Journal of Political Economy, 100(4), 801-817.

Ledyard, John. 1995. “Public goods: A Survey of Experimental Research.” The Handbook of Experimental Economics. J. Kagel and A. Roth Eds., Princeton, Princeton University Press. 111-194.

Levitt, Steven D., and John A. List. 2007. "What do Laboratory Experiments Measuring Social Preferences Reveal about the Real World.” Journal of Economic Perspectives, 21(2), 153174.

Lewis, H. B.. 1971. Shame and Guilt Neurosis. New York: International Universities Press.

Masclet, David, Charles Noussair, Steven Tucker, and Marie-Claire Villeval. 2003. “Monetary and Nonmonetary Punishment in the Voluntary Contributions Mechanism.” American Economic Review, 93(1), 366-379.

Noussair, Charles, and Steven Tucker. 2005. “Combining Monetary and Social Sanctions to Promote Cooperation.” Economic Inquiry, 43(2), 649-660.

Noussair, Charles, and Steven Tucker. 2007. "Public Observability of Decisions and Voluntary Contributions in a Multi-Period Context.” Public Finance Review, 35(2), 176-198. 
Ostmann, Axel. 1998. “External Control May Destroy the Commons.” Rationality and Society, 10(1): 103-122.

Ostrom, Elinor. 2000. “Collective Action and the Evolution of Social Norms.” Journal of Economic Perspectives, 14(3): 137-158.

Ostrom, Elinor, James Walker and Roy Gardner. 1992. “Covenants With and Without a Sword: Self-Governance is Possible.” American Political Science Review, 86(2): 404-417.

Rege, Mari, and Kjetil Telle. 2004. “The Impact of Social Approval and Framing on Cooperation in Public Goods Situations.” Journal of Public Economics, 88(7-8), 1625-1644.

Tangney, J. P., and, R. Dearing. 2002. Shame and Guilt. New York: The Guilford Press.

Tangney, J. P., R. S. Miller, L. Flicker, and D. H. Barlow. 1996. “Are Shame, Guilt and Embarrassment Distinct Emotions?” Journal of Personality and Social Psychology, 70, 12561269.

Velez, Maria Alejandra, James J. Murphy and John K. Stranlund. Forthcoming. “Centralized and Decentralized Management of Local Common Resources in the Developing World: Experimental Evidence from Fishing Communities in Colombia.” Economic Inquiry. 
Yamagishi, Toshio. 1986. “The Provision of a Sanctioning System as a Public Good.” Journal of Personality and Social Psychology, 51(1), 110-116. 


\section{Endnotes}

1 It is important to note that these notions of shame and guilt are not universally accepted among social scientists. The definitions we use tend to be accepted by economists, anthropologists, and political scientists who consider shame as a more "public" emotion than guilt. "Shame is seen as arising from public exposure and disapproval of some shortcoming or transgression, whereas guilt is seen as a more "private” experience arising from selfgenerated pangs of conscience” (Tangney and Dearing, 2002:14). According to some psychologists, however, this distinction is not clear cut, because it is possible to experienced solitary shame. Lewis (1971:30) makes the following distinction between guilt and shame: "The experience of shame is directly about the self, which is the focus of evaluation. In guilt, the self is not central object of negative evaluation, but rather the thing done or undone is the focus. In guilt, the self is negatively evaluated in connection with something but is not itself the focus of experience”. However, in a study by Tangney et al. (1996) that attempted to distinguish shame and guilt, they found that subjects felt "scrutinized" by others when they felt shame. This is consistent with our distinction in which shame is produced by social observation.

2 In a similar literature, sanctions within groups (as opposed to external sanctions that would be imposed for violations of regulatory controls) are costly both for individual punishers and for those being punished (e.g. Yamagishi 1986, Ostrom, Walker and Gardner 1992, Fehr and Gaechter 2000, Falk et al. 2001, Masclet et al. 2001). Noussair and Tucker (2005) find that the availability of monetary and non-monetary sanctions leads to higher contributions and group welfare than the availability of either alone. 
3 Bohnet and Frey (1999) find a similar result in dictator and prisoner's dilemma games.

4 We share the concerns of Levitt and List (2007) and others that laboratory experiments with university students playing abstract games may not produce outcomes that are valid predictors of real world behavior in some contexts. Using the taxonomy of Harrison and List (2004), our experiments are framed field experiments. Our experiment closely mirrors the natural occurring dilemma that concerns us, and our subject pool was drawn from populations in which small scale fishing from a local fishery is the main economic activity.

5 To be clear, we only claim to have attempted to induce feelings of guilt, shame, or related emotions. We do not know if the subjects in our experiments actually experienced these emotions.

6 Assignment to groups was not completely random. Members of the same household were not allowed in the same group and we tried to ensure that other relatives were in separate groups.

7 The experiment instructions are in the appendix. The instructions were first written in English, and then translated to Spanish. Another individual then translated the instructions back to English to minimize translation errors.

8 In July of 2005 one US dollar was equivalent to 2,330 Colombian pesos. A day's wage in the fishery industry or in agriculture on the islands of San Andres and Providencia was about 15,000 pesos

9 We use expected, rather than actual, earnings since at the time of the contribution decisions, individuals still face uncertainty about audits. 
${ }^{10}$ We can compare our Baseline results to the results of other standard public good games with similar parameters, group size and marginal benefits of contributions (Ledyard 1995, Fehr and Schmidt 1999 and Davis and Holt 1992). Average contributions in other experiments tend to start at around $40 \%-60 \%$ of the initial endowment and decline over time to $10-30 \%$. In our results, average contributions are in the 50\%-60\% range over all rounds. Interestingly, the "endgame effect" in which contributions fall considerably in the last period that is often observed is not present in our Baseline experiments. Since our Baseline treatment is similar to many other voluntary contribution experiments, we attribute our different results to the fact that we conducted framed field experiments instead of an abstract public goods game with university students.

${ }^{11}$ Unless otherwise noted, statistical comparisons of regression coefficients were conducted with Wald $\chi^{2}$ tests. 
Table 1: Experimental Design

\begin{tabular}{lll}
\hline Treatment & & Description \\
\hline Baseline & Baseline + & Standard linear public goods game \\
Frame & Baseline + Frame + & $\begin{array}{l}\text { Public reminder about benefits of cooperation } \\
1 / 5 \text { chance of receiving private reminder of the } \\
\text { social losses resulting from the individual's } \\
\text { noncooperative behavior }\end{array}$ \\
Shame & Baseline + Frame + Guilt + & $\begin{array}{l}1 / 5 \text { chance of receiving public announcement } \\
\text { of the social losses resulting from the } \\
\text { individual's noncooperative behavior }\end{array}$ \\
Low Penalty & Baseline + Frame + Guilt + & $\begin{array}{l}1 / 5 \text { chance of incurring a } 1 \text { token per unit } \\
\text { penalty for noncooperative behavior }\end{array}$ \\
High Penalty & Baseline + Frame + Guilt + & $\begin{array}{l}1 / 5 \text { chance of incurring a } 4 \text { token per unit } \\
\text { penalty for noncooperative behavior }\end{array}$ \\
\hline
\end{tabular}


Table 2: Summary Statistics

\begin{tabular}{lcc}
\hline Treatment & $\begin{array}{c}\text { Average } \\
\text { Contributions }\end{array}$ & $\begin{array}{c}\text { Average } \\
\text { Earnings }\end{array}$ \\
\hline Baseline & 14.6 & 39.6 \\
& $(6.3)$ & $(6.3)$ \\
Frame & 16.2 & 41.2 \\
& $(8.0)$ & $(8.0)$ \\
Guilt & 16.9 & 41.9 \\
& $(7.6)$ & $(7.6)$ \\
Shame & 20.2 & 45.2 \\
& $(6.7)$ & $(6.7)$ \\
Low & 18.2 & 41.8 \\
& $(7.7)$ & $(7.0)$ \\
High & 18.5 & 38.3 \\
& $(7.9)$ & $(7.1)$ \\
\hline
\end{tabular}

Standard deviations in parentheses. 
Table 3: Random Effects Tobit Models of Individual Contributions to Group Project and Expected Earnings

\begin{tabular}{|c|c|c|c|c|c|c|}
\hline \multirow[b]{2}{*}{ Variable } & \multicolumn{3}{|c|}{ Contributions } & \multicolumn{2}{|c|}{$\begin{array}{l}\text { Expected } \\
\text { Earnings }\end{array}$} & \multirow[b]{2}{*}{ Std. Error } \\
\hline & Coeffici & ent & $\begin{array}{c}\text { Std. } \\
\text { Error }\end{array}$ & Coeffi & cient & \\
\hline Constant (Baseline) & 14.90 & $* * *$ & 1.32 & 39.62 & $* * *$ & 0.85 \\
\hline First $\times$ Frame & 2.10 & & 1.93 & 1.67 & & 1.26 \\
\hline First $\times$ Guilt & 2.46 & & 1.93 & 1.59 & & 1.26 \\
\hline First $\times$ Shame & 6.32 & $* * *$ & 1.94 & 4.59 & $* * *$ & 1.26 \\
\hline First $\times$ High Penalty & 8.67 & $* * *$ & 1.97 & 0.34 & & 1.26 \\
\hline First $\times$ Low Penalty & 5.57 & $* * *$ & 1.93 & 3.08 & $* * *$ & 1.26 \\
\hline Middle $\times$ Frame & 2.40 & & 1.93 & 1.57 & & 1.26 \\
\hline Middle $\times$ Guilt & 2.64 & & 1.93 & 1.87 & & 1.26 \\
\hline Middle $\times$ Shame & 8.78 & $* * *$ & 1.95 & 6.20 & $* * *$ & 1.26 \\
\hline Middle $\times$ High Penalty & 7.03 & $* * *$ & 1.96 & -1.26 & & 1.26 \\
\hline Middle $\times$ Low Penalty & 4.83 & $* * *$ & 1.93 & 1.96 & & 1.26 \\
\hline Last $\times$ Frame & 2.42 & & 1.93 & 1.37 & & 1.26 \\
\hline Last $\times$ Guilt & 4.84 & $* * *$ & 1.94 & 3.26 & $* * *$ & 1.26 \\
\hline Last $\times$ Shame & 8.87 & $* * *$ & 1.95 & 5.99 & $* * *$ & 1.26 \\
\hline Last $\times$ High Penalty & 5.59 & $* * *$ & 1.96 & -2.93 & $* * *$ & 1.26 \\
\hline Last $\times$ Low Penalty & 4.60 & $* *$ & 1.93 & 1.56 & & 1.26 \\
\hline
\end{tabular}

Asterisks reflect $p$-values: $* p \leq 0.10 ; * * p \leq 0.05$; $* * * p \leq 0.01$. The constant is interpreted as average contributions or earnings under the Baseline treatment. The individual random effects are not reported and are available upon request. 
Figure 1: Average Individual Contributions to Group Project by Treatment

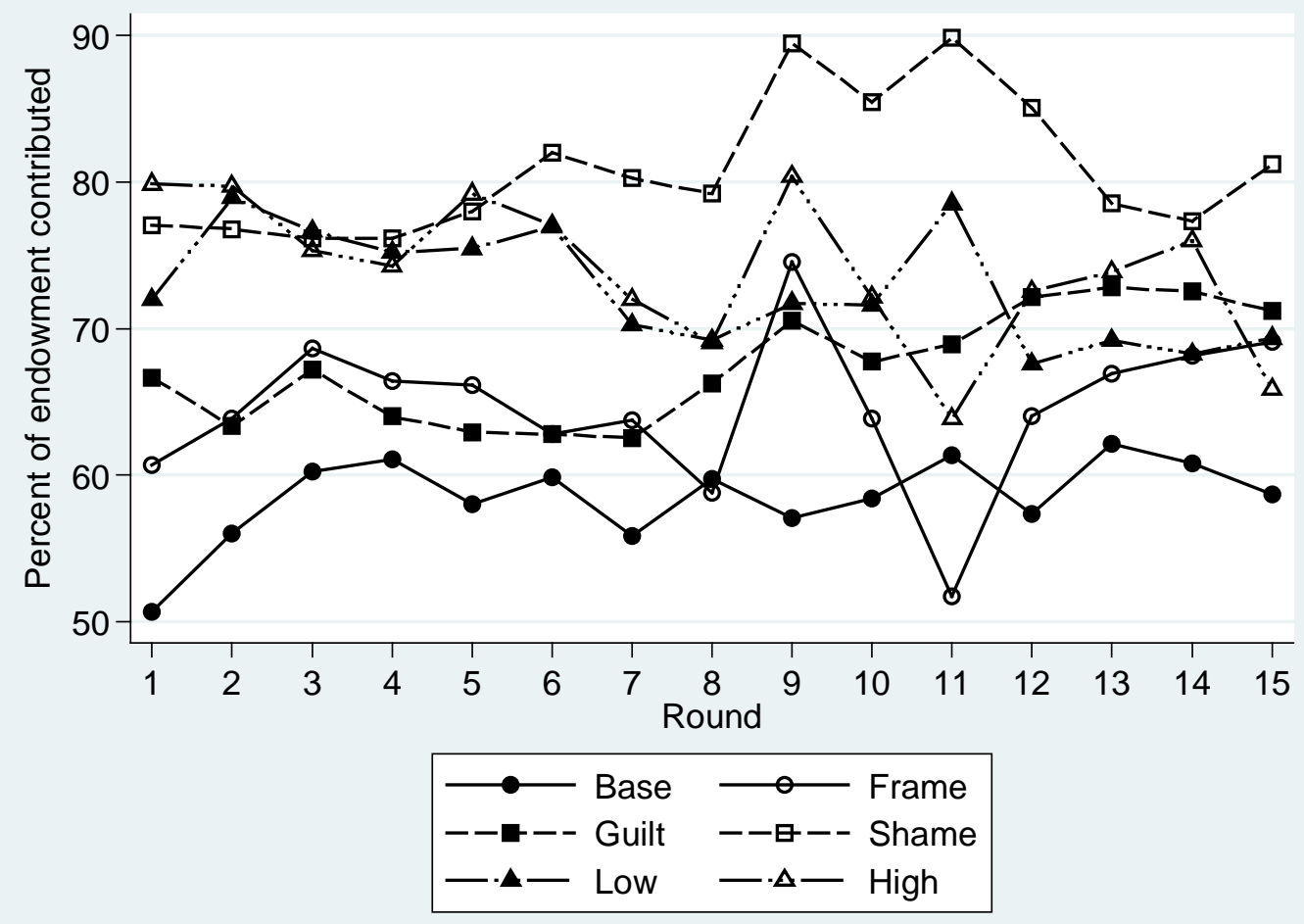


Figure 2: Average Individual Expected Earnings by Treatment

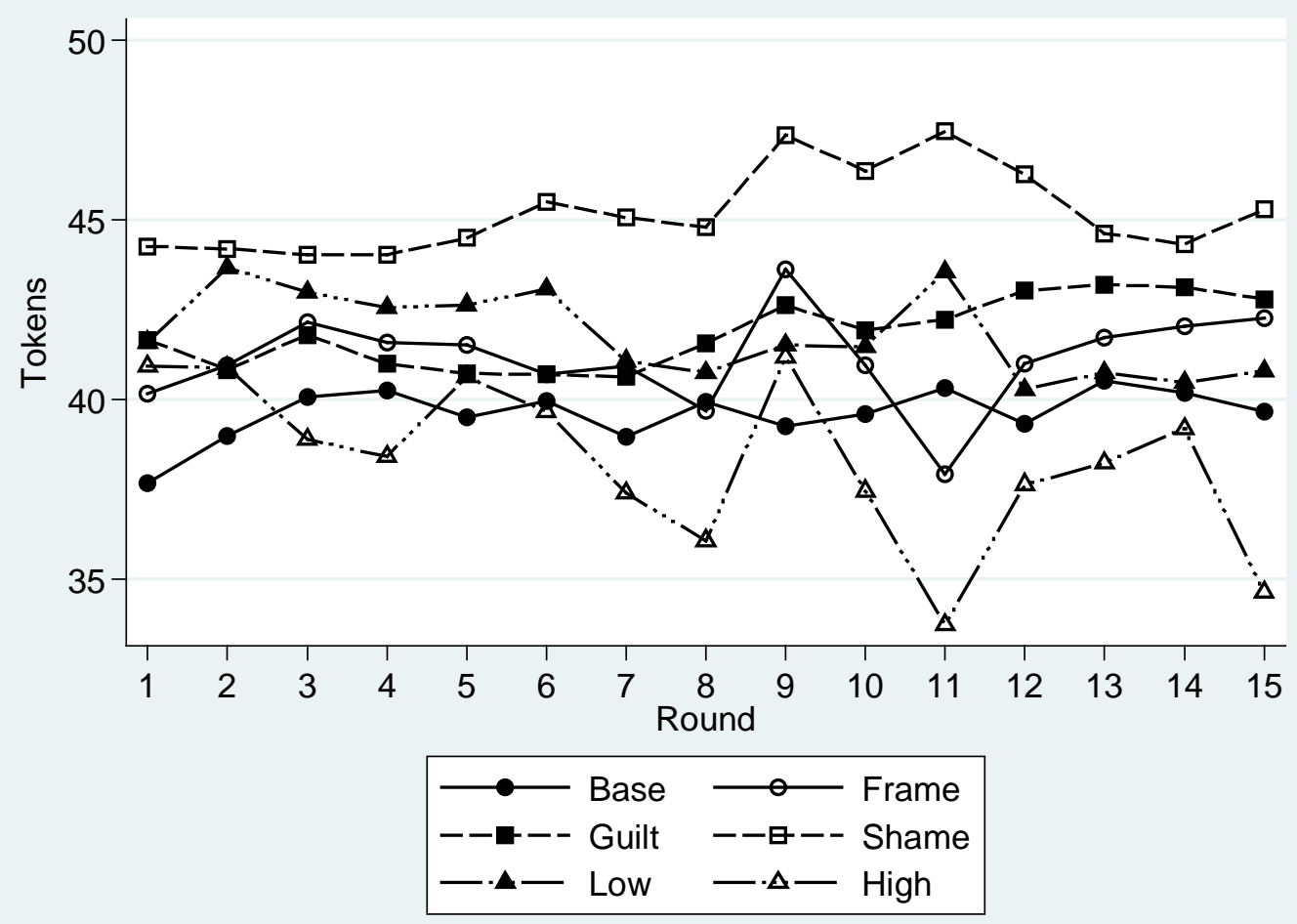


Figure 3: Distribution of individual group contribution decisions by treatment

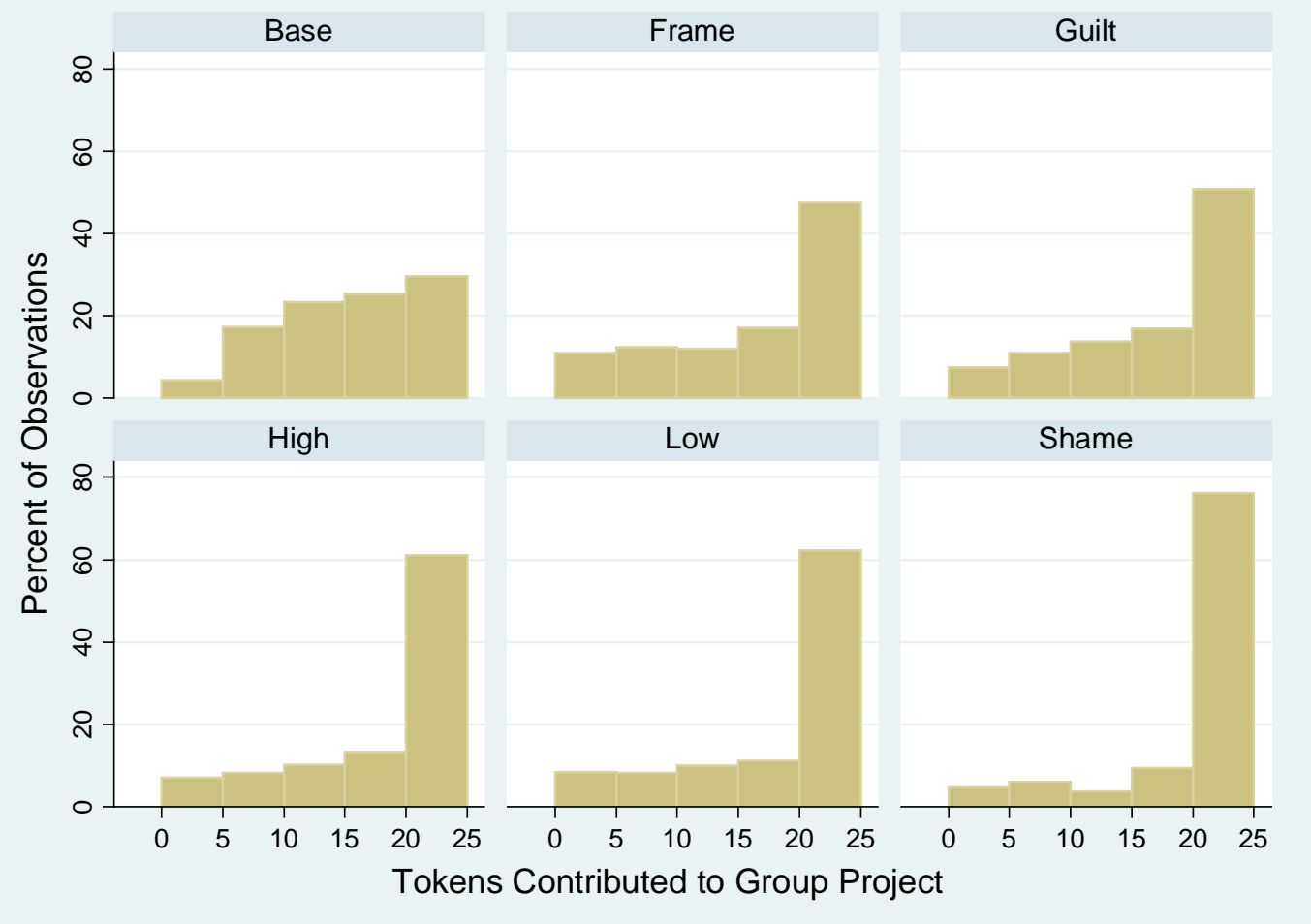

